\title{
The role of hypoxia-inducible factors in leukemias
}

\author{
Donata Szymczak ${ }^{D}$, Jarosław Dybko, ${ }^{A, D}$, Kazimierz Kuliczkowski ${ }^{D, E}$ \\ Department of Hematology, Wroclaw Medical University, Poland \\ A - research concept and design; $B$ - collection and/or assembly of data; $C$ - data analysis and interpretation; \\ $D$ - writing the article; $E$ - critical revision of the article; $F$ - final approval of the article
}

\section{Address for correspondence \\ Jarosław Dybko \\ E-mail: dybko@post.pl}

Funding sources

Medical University charter activities (ST-778)

Conflict of interest

None declared

Received on December 13, 2016

Reviewed on January 9, 2017

Accepted on March 2, 2017

\begin{abstract}
Hypoxia, understood as low partial oxygen pressure, has become one of the most explored fields in recent years. Cellular response to hypoxia is mediated by hypoxia-inducible factors (HIFs) - potent transcription regulators, and their downstream pathways. In general, HIFs modify energy metabolism, inflammation and immune response, enhance cancer invasion, metastasis, resistance to treatment, and relapse. The influence of HIFs on the progression of leukemia is still under investigation in various studies, but in mice and some human models HIFs have been recognized as leukemia immortalizers by promoting leukemic stem cell quiescence and inhibiting their cell cycle. This makes leukemic stem cells resistant to most known treatment approaches. The role of HIFs in solid tumors and leukemia makes them almost ideal targets for an anticancer treatment. Although the first attempts with new molecules are encouraging, there is a need to investigate the ambiguous role of HIFs to develop a modern antileukemic treatment.
\end{abstract}

Key words: leukemia, hypoxia, hypoxia-inducible factor-1

DOI

10.17219/acem/69261

\section{Copyright}

Copyright by Author(s)

This is an article distributed under the terms of the

Creative Commons Attribution Non-Commercial License

(http://creativecommons.org/licenses/by-nc-nd/4.0/) 
Leukemias remain an issue for contemporary medicine. The huge success in chronic myeloid leukemia (CML) treatment has not yet been matched by treatments for acute leukemias. Even tyrosine kinase inhibitors (TKI) - the main players in CML treatment - are not able to eradicate leukemic stem cells (LSCs). LSCs are a small subset of quiescent, self-renewable cells capable of re-establishing the whole tumor after chemotherapy. LSCs share marrow niches with hematopoietic stem cells (HSCs), but the niches are also inhabited by mesenchymal stem cells, bone cells, immune cells, and other cell types. The marrow microenvironment contributes considerably to the protection and development of leukemic cells. The bone marrow hematopoietic niche is characterized by low partial oxygen pressure, and this is essential to retaining HSCs, LSCs and other progenitor cells for long periods. Hypoxia is a very strong stimulus for adaptive cell changes mediated by the hypoxia-inducible factor (HIF) family. It has been shown that through HIFs, hypoxia optimizes solid tumor growth via metabolic modifications, stimulation of angiogenesis, cancer stem cell (CSC) maintenance and differentiation, and modification of the function of inflammatory cells. However, in leukemias, the role of hypoxia remains unclear, and the influence of HIFs on leukemogenesis is still controversial. On the other hand, some research has established the influence of HIFs on leukemic cell proliferation and resistance to chemotherapy. This paper attempts to summarize current knowledge about the role of hypoxia and HIFs in leukemias.

\section{Hypoxia}

Hypoxia is defined as a state of reduced or inadequate oxygen availability. Although different tissues and cells have varying degrees of susceptibility to hypoxia, at the cellular level, hypoxia and hypoxic responses generally occur at $\mathrm{PO}_{2} \leq \sim 1 \mathrm{kPa}\left(\leq \sim 7-10 \mathrm{~mm} \mathrm{Hg}\right.$ or $\left.\sim 1 \% \mathrm{O}_{2}\right) .{ }^{1}$ There are multiple physiologic and pathological contexts in which cells experience conditions of insufficient oxygen availability. ${ }^{2}$

Hypoxia has been reported to contibute in a variety of pathological states, including solid tumors with incomplete neoplasmatic vascularization; ischemic injury, such as myocardial infarction or transplants; and obesity with impaired adipose tissue metabolism. ${ }^{2}$ Other conditions that can be added to this list include vascular diseases (e.g., sickle cell disease), obstructive sleep apnea and chronic infection (e.g., granulomas).

Tissue oxygen concentration is much lower than in arterial blood en riched with oxygen from the air in the lungs. Tumor cells are not only prepared to survive total anoxia, but are skilled at taking advantage of the state to ensure uninhibited and uncontrolled growth through completely altered (but impaired) metabolism. ${ }^{3}$ Local oxygen concentration plays a leading role in tumor progression due to impaired and incomplete vessel networks, resulting in reduced cell nutrition in hypoxic zones. Low oxygen levels cause the activation of mTOR kinase 1 (mTORC1) and modify tumor metabolism through the HIF signaling pathway, leading to tumor growth. ${ }^{4}$

\section{The role of hypoxia-inducible factors}

As Semenza wrote: "[HIF] transcription factors are master regulators of the cellular response to hypoxia and coordinate a transcriptional program that ensures optimal functional, metabolic, and vascular adaptation to $\mathrm{O}_{2}$ shortages". ${ }^{5}$ HIF- $1 \alpha$ is also known to be responsible for cancer angiogenesis, growth and survival, glucose metabolism, invasion and metastasis, and immune regulation via the control of Th17/Treg balance. ${ }^{6-10}$ HIF- $2 \alpha$ is also expressed in a variety of cells, including endothelial cells and immune cells such as tumor-associated macrophages, and is reported to play an opposite role to HIF-1 $\alpha$ in the regulation of angiogenesis, but mainly in iron metabolism, erythrocytosis control, and somatic stem cell self-renewal. ${ }^{11-16}$

HIF is a heterodimeric complex consisting of 2 subunits: an oxygen-sensitive HIF- $\alpha$ and an unchangeable oxygen-stable HIF- $\beta$ (aryl hydrocarbon receptor nuclear transporter - ARNT). ${ }^{17}$ Both subunits are members of the basic helix-loop-helix (bHLH) PAS family of transcription factors. ${ }^{17}$ Three HIF- $\alpha$ homologs have been discovered: HIF- $1 \alpha$, HIF- $2 \alpha$ and less known HIF- $3 \alpha \cdot{ }^{18-20}$ HIF- $1 \alpha$ and HIF- $2 \alpha$ heterodimerize to HIF- $1 \beta$ and translocate to the nucleus, where the complex is bound to hypoxia response elements (HREs) in the promoters of target genes. When oxygen is available, prolyl-hydroxylases (PHDs) are active and HIF1- $\alpha$ is degraded by the PHD-mediated oxygenhydroxylation of proline (Pro-403 or Pro-564). ${ }^{21}$ The hydroxylated HIF1- $\alpha$ is recognized by the von Hippel-Lindau protein (pVHL), which is the recognition component of an E3 ubiquitin-protein ligase. This leads to ubiquitination and consequent degradation by proteasome. ${ }^{21}$ In hypoxic conditions, PHDs are inactivated, which leads to HIF- $\alpha$ accumulation. However, cells are doubly protected against HIF activation effects, and the shield is factor-inhibiting HIF (FIH) hydroxylating asparagine residues in HIF1- $\alpha$ and HIF- $2 \alpha$, which prevents HIFs from building active transcriptional complexes with cofactors. ${ }^{22}$ Both PHDs and FIH require a-ketoglutarate (2-oxoglutarate) as a cosubstrate. On the other hand, hypoxia diminishes PHDand FIH-dependent HIF- $\alpha$ hydroxylation, resulting in full activation of the HIF- $\alpha$ pathway. ${ }^{23}$

HIF1- $\alpha$ expression is also regulated by growth factors, cytokines and other signaling pathways, such as the phosphatidylinositide 3-kinase (PI3K) pathway and mitogenactivated protein kinase (MAPK) pathway. HIF1- $\alpha$ plays a role in cancer progression by activating the transcriptional programs to maintain the ability to self-renew and the multipotency of cancer stem cells in a hypoxic 
environment. ${ }^{24}$ This has been described for renal cell cancer, hepatocellular cancer, colorectal cancer and other cancers. ${ }^{25-27}$

In the $\mathrm{O}_{2}$-independent mechanism of HIF stabilization, bacterial products are recognized by toll-like receptors (TLRs) expressed on myeloid cells, signaling through the nuclear factor-light-chain-enhancer of activated B cells $(\mathrm{NF}-\mathrm{kB})$ to increase HIF1- $\alpha$ transcription. ${ }^{28}$ Similarly, $\mathrm{T}$ cell receptor (TCR) ligation upon antigen presentation on T lymphocytes results in increased HIF1- $\alpha$ transcription and HIF-1 $\alpha$ protein accumulation, even in the presence of oxygen. The mechanism of HIF-1 $\alpha$ mRNA expression has not yet been identified, but activation of PI3K and mTOR seems to be involved in TCR-related activation of HIF- $1 \alpha{ }^{29}$ On the other hand, HIF-1 $\alpha$ controls the Th17/Treg balance by promoting transcription of $\mathrm{ROR} \gamma \mathrm{t}-\mathrm{a}$ key regulator of Th17 differentiation - and proteosomal degradation of forkhead box P3 (FOXP3) - a key regulator of Treg differentiation. This leads to a sustained proinflammatory and autoaggressive reaction. ${ }^{10}$

HIF transcriptional targets also include glycolysis and angiogenesis regulating genes, e.g., glucose transporter 1 (GLUT1), phosphoglycerate kinase 1 (PGK1) and vascular endothelial growth factor $(V E G F) .{ }^{30-32}$ As McNamee et al. wrote: "While some HIF-1 $\alpha$ targets are conserved across multiple cell types, HIF- $1 \alpha$ is also clearly capable of mediating cell type-specific transcriptional responses. HIF- $1 \alpha$ is regulated at multiple stages, including transcriptional, translational, and post-translational levels." 2

Hematopoietic stem cells (HSCs) are able to enter quiescence and are characterized by self-renewal capability, and HIF- $1 \alpha$ protein is reported to enhance these features. ${ }^{33}$ Conditional deletion of the HIF- $1 \alpha$ gene causes HSC proliferation and reduces self-renewal potential in serial transplantations. ${ }^{34}$ On the other hand, HSCs cultured in hypoxic conditions have increased quiescence in vitro and in vivo when the HIF-1 pathway is activated. ${ }^{35}$

HIF- $2 \alpha$ is not necessary for the function of adult HSCs in vivo. ${ }^{35,36}$ Human bone marrow CD34+ cells hardly express HIF- $2 \alpha$, but HIF- $2 \alpha$ itself has been identified as a STAT5 target gene in HSCs. STAT5 plays crucial roles in selfrenewal in mouse and human HSCs, and its persistent activation leads to leukemic transformation. ${ }^{37}$ As Forristal et al. wrote: "It is clear that normal adult mouse and human [bone marrow] hematopoietic cells in steady state have low levels of HIF- $2 \alpha$ ". ${ }^{35}$ HIF- $2 \alpha$ is also expressed by some hematological neoplastic cells, such as acute lymphoblastic leukemia (ALL) and acute myeloid leukemia (AML) cells. ${ }^{35,38-40}$

HIF- $2 \alpha$ is also an important transcriptional regulator of the cellular hypoxia response, including hypoxic regulation of erythropoietin (EPO) synthesis and macrophage function. ${ }^{12,41}$ The interaction between HIF-1 $\alpha$ and HIF$2 \alpha$ in hypoxic gene regulation remains unclear. However, these transcriptional regulators can have competitive or even antagonistic functions. ${ }^{2,42}$
In summary, the HIF complex can cause transactivation of the target genes, leading to cell adaptation to hypoxic conditions, and plays a crucial role in many processes including enhanced cell proliferation (renal and colorectal cancer), cancer vascularization via VEGF, metastases, glycolysis regulation multidrug resistance (MDR), HSC quiescence and self-renewal, and many other processes. All these pathways have been widely described for solid tumors, but the roles of HIFs in leukemia seem to be inconsistent and remain unclear.

\section{Leukemias, hypoxia and HIFs}

Leukemia is the uncontrolled and uninhibited proliferation of hematopoietic cells. Acute leukemias are defined by proliferation of immature hematopoietic cells that fail to differentiate and accumulate in bone marrow and other organs, inhibiting the growth of normal hematopoietic cells. Acute myeloid leukemia (AML) has a high risk of relapse, despite therapeutic advances. Most known treatments target cycling cells, so the concept of relapse deriving from a quiescent surviving population of cells has arisen. LSCs derive from HSCs homing to the most hypoxic bone marrow areas. ${ }^{43-45}$ As mentioned above, tissue oxygen concentration is much lower than in arterial blood enriched in $\mathrm{O}_{2}$ from the lungs. In bone marrow, the oxygen concentration is even lower than in other tissues, ranging from $<6 \%$ oxygen near blood vessels to anoxia in not vascularized regions. The components of the hematopoietic niche vary in oxygen level. ${ }^{45,46}$ The boosting role of hypoxia in rapid growth, proliferation, metabolism, metastases and mortality of solid tumors has been described. ${ }^{47}$ The role of hypoxia in leukemias is not as well established, but the hypoxic BM niche increases poor response to treatment. ${ }^{45}$

It is accepted that gradients of $\mathrm{O}_{2}$ from below $1 \%$ in the hypoxic niche to $6 \%$ in the sinusoidal cavity exist in human bone marrow. Hypoxia is essential for long-term HSC survival and function. ${ }^{48}$ Molecular regulation of the influence of hypoxia on HSCs has not been established yet, but some studies have shed new light on the crucial role of HIF1 in mediating the effect of hypoxia on HSCs. ${ }^{34}$

Resistance to standard treatment modalities leading to leukemia relapse may be related to increased HIF expression. ${ }^{49}$ Poor outcomes of antileukemic treatment have been linked with overexpression of HIF-1 $\alpha$ in some studies, including an impact on survival. ${ }^{50-52}$ In other studies, overexpression of HIF-1 $\alpha$ has simply been reported - in AML, acute lymphoblastic leukemia (ALL) and chronic myeloid leukemia (CML). ${ }^{34,35}$ Similarly, HIF-2 $\alpha$ overexpression has been described in both AML and ALL, but has not yet been correlated with outcomes. ${ }^{35}$

There is a variety of mechanisms and molecular pathways that allow both HIF- $1 \alpha$ and HIF- $2 \alpha$ to contribute to leukemia survival, including metabolism, promoting cells in quiescence and immune dysregulation. HIF- $1 \alpha$ 
also plays the opposite role, inhibiting the expression of tumor expression genes. ${ }^{34,53,54}$ Most of the widely used antileukemic drugs target cycling cells, so AML cells quiesced by HIFs become resistant to standard cytosine treatment. Another HIF-1 $\alpha$-mediated mechanism promoting leukemia resistance is LSC support, as in CML, T cell acute lymphoblastic leukemia (T-ALL) and AML. ${ }^{44}$ This is a vicious circle: on one hand, LSCs sheltered in naturally hypoxic bone marrow niches stabilize HIF- $1 \alpha$, on the other hand, that same HIF- $1 \alpha$ keeps them in quiescence and lets them survive any treatment, as in CML. ${ }^{55}$ Moreover, in AML cells, HIF-1 $\alpha$ is stabilized under normoxic conditions as well. ${ }^{56}$ HIF- $1 \alpha$ (in cooperation with the Notch pathway) is able to arm LSCs with a powerful tool: selfrenewal, which lets them survive all known treatment modalities. ${ }^{57}$

\section{Perspectives and conclusions}

Taking into account the data cited above, it has been assumed lately that HIF inhibitors or PHD stimulators/ enhancers could be a potent weapon in the antileukemic war. Some new agents have been tested; one of the first was echinomycin, which was known to inhibit HIF-1 $\alpha$ DNA binding activity. This antibiotic targets AML cells through apoptosis. Echinomycin has no impact on selfrenewal and differentiation of HSCs, which makes it a perfect drug to eradicate leukemia. ${ }^{58}$ Another well-known drug, L-ascorbic acid in high concentrations, has also been shown to inhibit the expression of HIF-1 $\alpha$ in CML cells. It is particularly important in CML treatment to find a molecule capable of impacting LSCs that are completely resistant to TKI-based modalities. EZN-2208 (pegylated SN38) has also been shown to inhibit the expression and transcriptional activity of HIF-1 $\alpha$ in APL. ${ }^{59}$ None of these molecules target HSCs. Another molecule, TH-302, is a hypoxia-activated prodrug that has been reported to preferentially decrease proliferation, reduce HIF- $1 \alpha$ expression and induce cell-cycle arrest in AML cells. ${ }^{60}$ This is an example of an alternative strategy "using" hypoxia to activate prodrugs in the bone marrow niche and target LSCs in their homeland.

On the other hand, some research has shown evidence that PHD inhibition can inhibit tumor growth and invasiveness. ${ }^{57}$ This data derives from solid tumor investigation; evidence is still needed in relation to leukemia, but those trials definitely demonstrated the complex and ambiguous role of HIFs in cancer.

This data corroborates the view that hypoxia and HIFmediated signaling play a crucial role in leukemia. As noted above, there are some confusing and even contrary results, but most mouse trials have unequivocally confirmed the proleukemic role of HIFs. Therefore, it can be assumed that HIFs inhibitors may potentially be successful in treating human leukemia.

\section{References}

1. Jiang BH, Semenza GL, Bauer C, Marti HH. Hypoxia-inducible factor 1 levels vary exponentially over a physiologically relevant range of $\mathrm{O} 2$ tension. Am J Physiol. 1996;271:C1172-C1180.

2. McNamee EN, Korns Johnson D, Homann D, Clambey ET. Hypoxia and hypoxia-inducible factors as regulators of T cell development, differentiation, and function. Immunol Res. 2013;55:58-70.

3. Parks SK, Cormerais Y, Marchiq I, Pouyssegur J. Hypoxia optimises tumour growth by controlling nutrient import and acidic metabolite export. Mol Aspects Med. 2016;47-48:3-14.

4. Courtnay R, Ngo DC, Malik N, Ververis K, Tortorella SM, Karagiannis TC. Cancer metabolism and the Warburg effect: The role of HIF-1 and PI3K. Mol Biol Rep. 2015;42:841-51.

5. Semenza GL. Oxygen sensing, homeostasis, and disease. $N$ Engl J Med. 2011;365:537-547.

6. Otrock ZK, Hatoum HA, Awada AH, Ishak RS, Shamseddine Al. Hypoxia-inducible factor in cancer angiogenesis: Structure, regulation and clinical perspectives. Crit Rev Oncol Hematol. 2009;70:93-102.

7. Semenza GL. Defining the role of hypoxia-inducible factor 1 in cancer biology and therapeutics. Oncogene. 2010;29:625-634.

8. Semenza GL. Regulation of cancer cell metabolism by hypoxia-inducible factor 1. Semin Cancer Biol. 2009;19:12-16.

9. Semenza GL. Hypoxia-inducible factors: Mediators of cancer progression and targets for cancer therapy. Trends Pharmacol Sci. 2012;33:207-214.

10. Dang EV, Barbi J, Yang HY, et al. Control of $\mathrm{T}(\mathrm{H}) 17 / \mathrm{T}(\mathrm{reg})$ balance by hypoxia-inducible factor 1. Cell. 2011;146:772-784.

11. Hu CJ, Wang LY, Chodosh LA, Keith B, Simon MC. Differential roles of hypoxia-inducible factor 1alpha (HIF-1alpha) and HIF-2alpha in hypoxic gene regulation. Mol Cell Biol. 2003;23:9361-9374.

12. Imtiyaz HZ, Williams EP, Hickey MM, et al. Hypoxia-inducible factor 2alpha regulates macrophage function in mouse models of acute and tumor inflammation. J Clin Invest. 2010;120:2699-2714.

13. Talks KL, Turley H, Gatter KC, et al. The expression and distribution of the hypoxia-inducible factors HIF-1alpha and HIF-2alpha in normal human tissues, cancers, and tumor-associated macrophages. Am J Pathol. 2000;157:411-421.

14. Haase VH. Hypoxic regulation of erythropoiesis and iron metabolism. Am J Physiol Renal Physiol. 2010;299:F1-13.

15. Franke K, Gassmann M, Wielockx B. Erythrocytosis: The HIF pathway in control. Blood. 2013;122:1122-1128.

16. Ito K, Suda T. Metabolic requirements for the maintenance of selfrenewing stem cells. Nat Rev Mol Cell Biol. 2014;15:243-256.

17. Wang GL, Jiang BH, Rue EA, Semenza GL. Hypoxia-inducible factor 1 is a basic-helix-loop-helix-PAS heterodimer regulated by cellular $\mathrm{O} 2$ tension. Proc Natl Acad Sci U S A. 1995;92:5510-5514.

18. Semenza GL, Agani F, Booth G, et al. Structural and functional analysis of hypoxia-inducible factor 1. Kidney Int. 1997;51:553-555.

19. Tian H, McKnight SL, Russell DW. Endothelial PAS domain protein 1 (EPAS1), a transcription factor selectively expressed in endothelial cells. Genes Dev. 1997;11:72-82.

20. Yang SL, Wu C, Xiong ZF, Fang X. Progress on hypoxia-inducible factor-3: Its structure, gene regulation and biological function (Review). Mol Med Rep. 2015;12:2411-2416.

21. Huang LE, Gu J, Schau M, Bunn HF. Regulation of hypoxia-inducible factor 1alpha is mediated by an O2-dependent degradation domain via the ubiquitin-proteasome pathway. Proc Natl Acad SciU S A. 1998;95:7987-7992.

22. Majmundar AJ, Wong WJ, Simon MC. Hypoxia-inducible factors and the response to hypoxic stress. Mol Cell. 2010;40:294-309.

23. Greer SN, Metcalf JL, Wang Y, Ohh M. The updated biology of hypoxia-inducible factor. EMBO J. 2012;31:2448-2460.

24. Zhong H, Chiles K, Feldser D, et al. Modulation of hypoxia-inducible factor 1alpha expression by the epidermal growth factor/phosphatidylinositol 3-kinase/PTEN/AKT/FRAP pathway in human prostate cancer cells: Implications for tumor angiogenesis and therapeutics. Cancer Res. 2000;60:1541-1545.

25. Klatte T, Seligson DB, Riggs SB, et al. Hypoxia-inducible factor 1 alpha in clear cell renal cell carcinoma. Clin Cancer Res. 2007;13:73887393.

26. Dai CX, Gao Q, Qiu SJ, et al. Hypoxia-inducible factor-1 alpha, in association with inflammation, angiogenesis and MYC, is a critical 
prognostic factor in patients with HCC after surgery. BMC Cancer. 2009;9:418.

27. Rajaganeshan R, Prasad R, Guillou PJ, Poston G, Scott N, Jayne DG The role of hypoxia in recurrence following resection of Dukes' $B$ colorectal cancer. Int J Colorectal Dis. 2008;23:1049-1055.

28. D'Ignazio L, Bandarra D, Rocha S. NF-kB and HIF crosstalk in immune responses. FEBS J. 2016;283:413-424.

29. Han S, Xu W, Wang Z, et al. Crosstalk between the HIF-1 and Toll-like receptor/nuclear factor-KB pathways in the oral squamous cell carcinoma microenvironment. Oncotarget. 2016;7:37773-37789.

30. Chen C, Pore N, Behrooz A, Ismail-Beigi F, Maity A. Regulation of glut1 mRNA by hypoxia-inducible factor-1. Interaction between $\mathrm{H}$-ras and hypoxia. J Biol Chem. 2001;276:9519-9525.

31. Semenza GL, Roth PH, Fang HM, Wang GL. Transcriptional regulation of genes encoding glycolytic enzymes by hypoxia-inducible factor 1. J Biol Chem. 1994;269:23757-23763.

32. Ryan HE, Lo J, Johnson RS. HIF-1 alpha is required for solid tumor for mation and embryonic vascularization. EMBO J. 1998;17:3005-3015.

33. Takubo K, Goda N, Yamada W, et al. Regulation of the HIF-1alpha level is essential for hematopoietic stem cells. Cell Stem Cell. 2010;7:391402.

34. Zhang H, Li H, Xi HS, Li S. HIF1a is required for survival maintenance of chronic myeloid leukemia stem cells. Blood. 2012;119:2595-2607.

35. Forristal CE, Brown AL, Helwani FM, et al. Hypoxia inducible factor (HIF)-2a accelerates disease progression in mouse models of leukemia and lymphoma but is not a poor prognosis factor in human AML. Leukemia. 2015:29:2075-2085.

36. Guitart AV, Subramani C, Armesilla-Diaz A, et al. Hif-2a is not essentia for cell-autonomous hematopoietic stem cell maintenance. Blood. 2013;122:1741-1745.

37. Fatrai S, Wierenga AT, Daenen SM, Vellenga E, Schuringa JJ. Identification of HIF2alpha as an important STAT5 target gene in human hematopoietic stem cells. Blood. 2011;117:3320-3330.

38. Zou J, Li P, Lu F, et al. Notch1 is required for hypoxia-induced proliferation, invasion and chemoresistance of T-cell acute lymphoblastic leukemia cells. J Hematol Oncol. 2013;6:3.

39. Kawada H, Kaneko M, Sawanobori M, et al. High concentrations of L-ascorbic acid specifically inhibit the growth of human leukemic cells via downregulation of HIF-1a transcription. PloS One. 2013;8:e62717.

40. Wang Y, Liu Y, Malek SN, Zheng P, Liu Y. Targeting HIF1a eliminates cancer stem cells in hematological malignancies. Cell Stem Cell. 2011;8:399-411.

41. Rankin EB, Biju MP, Liu Q, et al. Hypoxia-inducible factor-2 (HIF-2) regulates hepatic erythropoietin in vivo. J Clin Invest. 2007;117:1068-1177.

42. Keith B, Johnson RS, Simon MC. HIF1a and HIF2a: Sibling rivalry in hypoxic tumour growth and progression. Nat Rev Cancer. 2011;12: 9-22.

43. Schepers K, Campbell TB, Passegue E. Normal and leukemic stem cell niches: Insights and therapeutic opportunities. Cell Stem Cell. 2015;16:254-267.
44. Tabe Y, Konopleva M. Advances in understanding the leukaemia microenvironment. Br J Haematol. 2014;164:767-778.

45. Deynoux M, Sunter N, Herault O, Mazurier F. Hypoxia and hypoxiainducible factors in leukemias. Front Oncol. 2016;6:41.

46. Chow DC, Wenning LA, Miller WM, Papoutsakis ET. Modeling pO(2) distributions in the bone marrow hematopoietic compartment. I. Krogh's model. Biophys J. 2001;81:675-684.

47. Semenza GL. HIF-1 mediates metabolic responses to intratumoral hypoxia and oncogenic mutations. J Clin Invest. 2013;123:3664-3671.

48. Semenza GL. Oxygen-dependent regulation of mitochondrial respiration by hypoxia-inducible factor 1. Biochem J. 2007;405:1-9.

49. Mimeault M, Batra SK. Hypoxia-inducing factors as master regulators of stemness properties and altered metabolism of cancer- and metastasis-initiating cells. J Cell Mol Med. 2013;17:30-54.

50. Deeb G, Vaughan MM, Mclnnis I, et al. Hypoxia-inducible factor-1a protein expression is associated with poor survival in normal karyotype adult acute myeloid leukemia. Leukemia Res. 2011;35:579-584.

51. Song K, Li M, Xu XJ, et al. HIF-1a and GLUT1 gene expression is associated with chemoresistance of acute myeloid leukemia. Asian Pac J Cancer Prev. 2014;15:1823-1829.

52. Tong H, Hu C, Zhuang Z, Wang L, Jin J. Hypoxia-inducible factor-1a expression indicates poor prognosis in myelodysplastic syndromes. Leuk Lymphoma. 2012;53:2412-2418.

53. Simsek T, Kocabas F, Zheng J, et al. The distinct metabolic profile of hematopoietic stem cells reflects their location in a hypoxic niche. Cell Stem Cell. 2010;7:380-390.

54. Gao XN, Yan F, Lin J, et al. AML1/ETO cooperates with HIF1a to promote leukemogenesis through DNMT3a transactivation. Leukemia. 2015;29:1730-1740.

55. Ng KP, Manjeri A, Lee KL, et al. Physiologic hypoxia promotes maintenance of CML stem cells despite effective BCR-ABL1 inhibition. Blood. 2014;123:3316-3326.

56. Spinello I, Quaranta MT, Paolillo R, et al. Differential hypoxic regulation of the microRNA-146a/CXCR4 pathway in normal and leukemic monocytic cells: Impact on response to chemotherapy. Haematologica. 2015;100:1160-1171.

57. Belmonte M, Hoofd C, Weng AP, Giambra V. Targeting leukemia stem cells: Which pathways drive self-renewal activity in T-cell acute lymphoblastic leukemia? Curr Oncol. 2016;23:34-41.

58. Wang $Y$, Liu $Y$, Tang $F$, et al. Echinomycin protects mice against relapsed acute myeloid leukemia without adverse effect on hematopoietic stem cells. Blood. 2014;124:1127-1135.

59. Coltella N, Valsecchi R, Ponente M, Ponzoni M, Bernardi R. Synergistic leukemia eradication by combined treatment with retinoic acid and HIF inhibition by EZN-2208 (PEG-SN38) in preclinical models of PML-RARa and PLZF-RARa-driven leukemia. Clin Cancer Res. 2015;21:3685-3694.

60. Portwood S, Lal D, Hsu YC, et al. Activity of the hypoxia-activated prodrug, TH-302, in preclinical human acute myeloid leukemia models. Clin Cancer Res. 2013;19:6506-6519. 